\title{
ANALISA PENGARUH TECHNOLOGY ACCEPTANCE MODEL (TAM) PADA APLIKASI PENDAFTARAN PENILAIAN TRAINING RECORD BOOK (SMILE 05) STUDI PADA PUKP 05 SEMARANG
}

\author{
Arika Palapa $^{1 *}$, Iksan Saifudin ${ }^{2}$ \\ 1,2 Politeknik Ilmu Pelayaran Semarang, Jl. Singosari Raya No.2A, Wonodri, Kec. \\ Semarang Sel., Kota Semarang, Jawa Tengah 50242 \\ * Corresponding Author. E-mail : arikapalapa67@gmail.com. HP. +62 812-2816-138
}

\begin{abstract}
Abstrak
Tujuan spesifik penelitian ini adalah untuk menguji pengaruh Perceived ease of use, Perceived usefulness, dan Attitude toward using terhadap Actual usage peserta penilaian Training Record Book dalam menggunaan aplikasi pendaftaran berbasis online secara parsial. Penelitian ini menggunakan sampel peserta penilaian Training Record Book sebanyak 100 taruna dari tingkat Akademi maupun dari tingkat SMK Pelayaran. Berdasarkan hasil penelitian dapat disimpulkan sebagai berikut: (1) Perceived ease of use berpengaruh terhadap Attitude toward using, semakin mudah penggunaan suatu aplikasi, maka merubah sikap pengguna untuk tertarik menggunakannya. (2) Perceived usefulness berpengaruh positif dan signifikan terhadap Attitude toward using, semakin bermanfaat suatu aplikasi dalam mempercepat sebuah proses pekerjaan maka merubah sikap pengguna untuk tertarik menggunakannya. (3) Perceives ease of use berpengaruh positif dan signifikan terhadap Actual usage, semakin mudah penggunaan suatu aplikasi, maka pengguna tertarik meningkatkan frekuensi penggunaan sebagai rasa puas pengguna untuk menyampaikan rasa puasnya terhadap orang lain. (4) Perceived usefulness berpengaruh positif dan signifikan terhadap Actual usage, semakin bermanfaat suatu aplikasi dalam mempercepat sebuah proses pekerjaan maka membawa pengguna untuk tertarik meningkatkan frekuensi penggunaan. (5) Attitude toward using berpengaruh positif dan signifikan terhadap Actual usage, semakin positif sikapnya dalam penggunaan suatu aplikasi, maka membawa pengguna untuk tertarik meningkatkan frekuensi penggunaan.
\end{abstract}

Kata Kunci: Perceived ease of use, Perceived usefulness, Attitude toward using dan Actual usage.

\begin{abstract}
The specific purpose of this study is to examine the effect of perceived ease of use, perceived usefulness, and Attitude toward using on the Actual usage of participating in the Training Record Book assessment in using a partial onlinebased registration application. This study used a sample of 100 participating in the Training Record Book assessment, both from the Academy and the Vocational High School level. The sampling technique in this study was nonprobability sampling with a purposive sampling-method. Based on the research results, it can be concluded as follows: (1) Perceived ease of use affects Attitude toward using,
\end{abstract}


that the easier it is to use an application, it changes the user's attitude to be interested using it. (2) Perceived usefulness has a positive and significant effect on Attitude toward using, the more useful an application is in accelerating a work process, it changes the user's attitude to be interested in using it. (3) Perceives ease of use has a positive and significant effect on Actual usage, the easier it is to use an application, then brings users to be interested in increasing the frequency of use as a result of user satisfaction to convey their satisfaction to others. (4) Perceived usefulness has a positive and significant effect on Actual usage,more useful an application in accelerating a work process, so it will bring users to be interested in increasing the frequency of use. (5) Attitude toward using has a positive and significant effect on Actual usage, more positive the Attitude toward using an application, the more users are interested in increasing the frequency of use.

Keywords: Perceived ease of use, Perceived usefulness, Attitude toward using and Actual usage.

\section{PENDAHULUAN}

Perkembangan teknologi dan informasi yang demikian pesat menuntut pelaku pendidikan dan pengujian mampu dalam menghadapi tantangan berupa persaingan dalam pelayanan. Tuntutan untuk memberikan pelayanan yang maksimal dengan mempertimbangkan aspek efektifitas dan efisiensi sangat dikedepankan. Kecepatan dan ketepatan pelayanan merupakan aspek efesiensi kerja yang harus dimiliki agar kepuasan pengguna layanan dapat tercapai sehingga tetap loyal menggunakan produk atau jasa yang dimiliki (Tjiptono dkk, 2005: 55). Perkembangan teknologi informasi dan komunikasi khususnya pada sistem informasi telah melahirkan berbagai inovasi baru salah satunya adalah di bidang pelayanan pendaftaran ujian Training Record Book.

Perkembangan teknologi harus benar-benar dimanfaatkan untuk memaksimalkan kinerja agar dapat tetap bersaing. Teknologi informasi yang handal akan menyajikan informasi yang berkualitas sehingga memudahkan setiap proses kerja yang dilakukan. Konsep dalam penelitian ini adalah model berketerimaan teknologi (Technology Acceptance Model - TAM). Dalam TAM, penerimaan pemakai Sistim Informasi ditentukan oleh dua faktor kunci yaitu perceived usefulness dan perceived easy of use. Disebutkan oleh Fishbein dan Ajzen, 1975, Konsep TAM dikembangkan oleh (Davis, 1989), menawarkan sebuah teori sebagai landasan untuk mempelajari dan memahami perilaku pemakai dalam menerima dan menggunakan sistem informasi (Handayani, 2005). Model ini memiliki tujuan untuk menjelaskan faktor-faktor kunci dari perilaku pengguna teknologi informasi terhadap penerimaan pengadopsian teknologi informasi tersebut (Handayani, 2005). Melalui teori TAM dapat memahami bahwa reaksi dan persepsi penggunaan teknologi dapat mempengaruhi sikapnya dalam penerimaan penggunaan teknologi. Diharapkan dengan adanya prinsip TAM dapat meningkatkan kepuasan pengguna sistem. Penelitian ini bertujuan untuk menguji secara empiris pengaruh Technology Acceptance Model (TAM) 
pada aplikasi pendaftaran penilaian Training Record Book Smile 05 (studi pada PUKP 05 Semarang).

\section{KAJIAN LITERATUR}

\section{A. Pengertian Technology Acceptance Model (TAM)}

Berbagai definisi tentang model TAM seperti yang disebutkan oleh Davis et al. (1993) dan Theory of Reasoned Action Model (TRA) yang dipaparkan oleh Fishbein dan Ajzen (1975) telah mendominasi berbagai literatur dalam sistem informasi. Disebutkan bahwa pengaruh variabel-variabel dalam model TAM dan TRA dipengaruhi oleh keyakinan individu mengenai manfaat teknologi (Lewis et al., 2003). Kecanggihan dan kemodernan teknologi saat ini jika saja dimanfaatkan dengan baik dan maksimal maka pasti akan menghasilkan manfaat yang menghasilkan, misalnya kita bisa membuka lowongan pekerjaan dengan menggunakan teknologi internet khususnya kita bisa membuat pendaftaran online pada suatu kegiatan yang tidak memiliki bentuk fisik yang dinilai beresiko, sehingga akan mempermudah kita dalam membuka pendaftaran bagi peserta tersebut meskipun kita tidak memiliki banyak waktu karena media kontrol kita hanya via komputer, laptop, atau handphone. Pendaftaran online suatu kegiatan sekarang terus berkembang karena orang memikirkan waktu yang fleksibel untuk mendaftar lebih praktis tanpa datang langsung ke lokasi pendaftaran, sehingga dapat menghemat biaya dan waktu. Technology Acceptance Model (TAM) atau Model Penerimaan Teknologi merupakan salah satu teori tentang penggunaan sistem teknologi informasi yang sangat berpengaruh dan umumnya digunakan untuk menjelaskan penerimaan individual terhadap penggunaan sistem teknologi informasi (Jogiyanto, 2008: 111). Model TAM ditunjukkan pada Gambar 1.

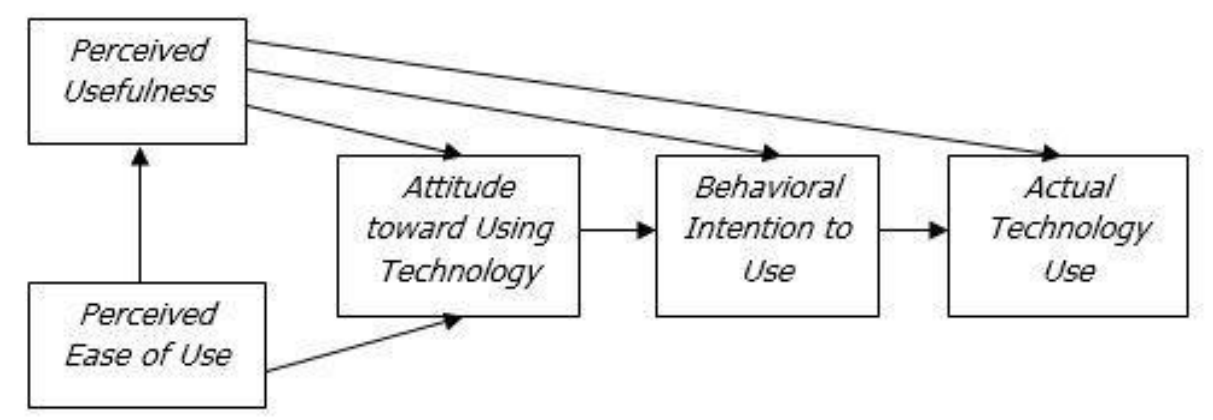

Gambar 1. Technology Acceptance Model (Jogiyanto, 2008: 113)

TAM memiliki 5 konstruk utama, yaitu: (1) Perceived usefulness (kegunaan), (2) Perceived ease of use (kemudahan penggunaan), (3) Attitude toward using technology (sikap), (4) Behavioral intention to use (intensi), dan (5) Actual technology use (penggunaan teknologi sesungguhnya).

\section{B. Pengertian Aplikasi Smile 05}

Setiap Taruna yang melaksanakan PRALA (Praktek Layar) akan di bekali dengan buku panduan yang biasa di kenal dengan buku TRB atau Training 
Record Book, yang mana buku ini merupakan buku panduan bagi seorang Taruna Prala, buku tersebut berisi tentang kompetensi apa saja yang harus di dapatkan taruna selama melaksanakan praktek di atas kapal, selama kurun waktu 12 bulan melaksanakan masa Pralanya. Setelah selesai melaksanakan Prala, maka buku panduan tersebut akan di uji oleh PUKP (Pelaksana Ujian Keahlian Pelaut) mengenai kemampuan taruna seperti yang di maksudkan dalam isi buku TRB. Dalam pelaksanaan pengujian PUKP 5 menggunakan aplikasi pendaftaran secara online untuk mempermudah proses pendaftaran, hal tersebut di karenakan wilayah kerja dari PUKP 5 yang sangat luas sehingga dengan keberadan aplikasi pendaftaran online tersebut diharapkan mampu membuat pendaftaran menjadi lebih efektif dan efisien. SMILE 05 adalah aplikasi berbasis web dengan alamat www.smile.pip-semarang.ac.id yang berfungsi untuk pendaftaran peserta ujian TRB (Training Record Book) secara online dan pemilihan periode ujian yang diinginkan serta terintegrasi dengan aplikasi pengujian TRB (Training Record Book) dengan nama Sistem Informasi Manajemen Peserta Ujian Training Record Book (SIMPUTRB).

\section{Review Penelitian Terdahulu}

Tabel 1. Review Penelitian Terdahulu

\begin{tabular}{|c|c|c|c|}
\hline & \multicolumn{3}{|c|}{$\begin{array}{c}\text { Penelitian yang menguji pengaruh Technology Acceptance Model (TAM) pada Aplikasi } \\
\text { Pendaftaran Ujian Training Record Book (SMILE 05) }\end{array}$} \\
\hline 1 & $\begin{array}{l}\text { Putu Ayu Mira } \\
\text { Witriyanti Wida. } \\
\text { Ni Nyoman Kerti } \\
\text { Yasa. } \\
\text { I Putu Gde } \\
\text { Sukaatmadja. }\end{array}$ & $\begin{array}{l}\text { APLIKASI MODEL TAM } \\
\text { (TECHNOLOGY } \\
\text { ACCEPTANCE } \\
M O D E L) P A D A \\
\text { PERILAKU PENGGUNA } \\
\text { INSTAGRAM }\end{array}$ & $\begin{array}{l}\text { the variables of perceived ease of use } \\
\text { and perceived usefulness has a positive } \\
\text { and significant impact on the Attitude } \\
\text { toward using. Perceived ease of use and } \\
\text { perceived usefulness also had a positive } \\
\text { and significant impact on Actual usage. } \\
\text { Attitude toward using has a positive and } \\
\text { significant impact on Actual usage. }\end{array}$ \\
\hline 2 & Arief Wibowo & $\begin{array}{l}\text { KAJIAN TENTANG } \\
\text { PERILAKU PENGGUNA } \\
\text { SISTEM INFORMASI } \\
\text { DENGAN } \\
\text { PENDEKATAN } \\
\text { TECHNOLOGY } \\
\text { ACCEPTANCE MODEL } \\
\text { (TAM) }\end{array}$ & $\begin{array}{l}\text { Perasaan menerima atau menolak muncul } \\
\text { menjadi dimensi sikap terhadap } \\
\text { penggunaan sistem informasi. Selain } \\
\text { sikap, diketahui ada beberapa faktor lain } \\
\text { yang dapat mempengaruhi perilaku user } \\
\text { terhadap penggunaan sistem informasi. } \\
\text { Penelitian ini akan mengkaji perilaku } \\
\text { pengguna sistem informasi di sebuah } \\
\text { institusi pendidikan tinggi berdasarkan } \\
\text { faktor-faktor yang mempengaruhinya } \\
\text { dengan pendekatan Technology } \\
\text { Acceptance Model (TAM). }\end{array}$ \\
\hline 3 & $\begin{array}{l}\text { Made Wahyu } \\
\text { Adhiputra }\end{array}$ & $\begin{array}{l}\text { APLIKASI TAM } \\
\text { TERHADAP PENGGUNA } \\
\text { LAYANAN INTERNET } \\
\text { BANKING }\end{array}$ & $\begin{array}{l}\text { Variabel Perceived ease of use dan } \\
\text { Perceived usefulness memiliki hubungan } \\
\text { positif dan signifikan secara langsung } \\
\text { terhadap Attitude toward using. } \\
\text { Variabel Perceived ease of use dan } \\
\text { Perceived usefulness memiliki hubungan } \\
\text { positif dan secara langsung terhadap Actual } \\
\text { Useage. } \\
\text { Attitude toward using memiliki hubungan }\end{array}$ \\
\hline
\end{tabular}

Majalah Ilmiah Bahari Jogja 73 | http://jurnal.amy.ac.id/index.php/MIBJ/ 
Penelitian yang menguji pengaruh Technology Acceptance Model (TAM) pada Aplikasi Pendaftaran Ujian Training Record Book (SMILE 05)

4 Dr. Dedi Rianto Rahadi

PERANAN TEKNOLOGI
INFORMASI DALAM
PENINGKATAN
PELAYANAN DI
SEKTOR PUBLIK

PERANAN TEKNOLOGI PENINGKATAN PELAYANAN DI SEKTOR PUBLIK positif dan significan secara langsung

terhadap Actual usage.

1. Perceived ease of use berpengaruh tidak signifikan dan positif Terhadap acceptance TI

2. Perceived ease of use berpengaru signifikan dan positif Terhadap Perceived Usefullness

3. Perceived Usefullness berpengaruh tidak signifikan dan negatif Terhadap acceptance TI

\section{Kerangka Pemikiran Teoritis}

Ada 4 konstruk yang digunakan dalam model TAM pada penelitian ini yaitu : Perceived ease of use, Perceived usefulness, Attitude toward using, dan Actual usage. Berdasarkan uraian tersebut diatas maka dapat disusun kerangka teoritis sebagai berikut :

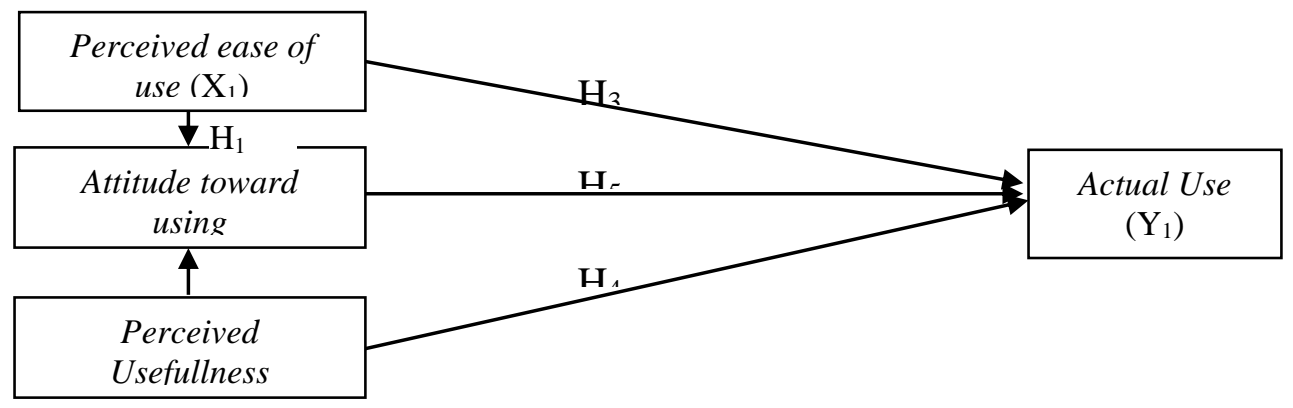

Gambar 2. Kerangka Pemikiran Teoritis

\section{METODE PENELITIAN}

Penelitian ini menggunakan rancangan penelitian kausal karena bertujuan untuk mendapatkan bukti sebab akibat antara variabel variabel penelitian yang terdiri atas Perceived ease of use, Perceived usefulness, Attitude toward using dan Actual usage. Ruang lingkup penelitian ini adalah bidang perilaku pengguna aplikasi pendaftaran online ujian Training Record Book (Smile 05), Subyek penelitian yaitu semua peserta ujian Training Record Book di wilayah kerja PUKP 05, sedangkan obyek dari penelitian ini adalah perilaku pengguna aplikasi Smile 05 yaitu perceived ease of use, perceived usefulness dan Attitude toward Using yang dikaitkan dengan Actual Usage.

\section{A. Populasi Penelitian}

Dalam penelitian ini yang menjadi populasi adalah Peserta Ujian Training Record Book di bawah PUKP 05 semarang yang berjumlah 100 orang. Penelitian ini teknik pengambilan sampel menggunakan teknik purposive sampling, kriteria dalam purposive sampling yang dimaksud yaitu : (1) Responden merupakan peserta ujian Training Record Book. (2) Responden 
memiliki akses internet. (3) Responden telah melakukan pendaftaran dengan menggunakan aplikasi Smile 05 atau aplikasi pendaftaran ujian TRB secara online.

\section{B. Definisi Konsep, Operasional Dan Pengukuran Variabel}

Tabel 2. Definisi Konsep, Operasional dan Pengukuran Variabel

\begin{tabular}{|c|c|c|c|}
\hline No & Variabel & Definisi Konsep & $\begin{array}{c}\text { Definisi Operasional } \\
\text { Indikator } \\
\end{array}$ \\
\hline 1. & $\begin{array}{l}\text { Perceived } \\
\text { usefulness } \\
\text { (X1) }\end{array}$ & $\begin{array}{l}\text { Ukuran di mana penggunaan suatu } \\
\text { teknologi dipercaya dapat mendatangkan } \\
\text { manfaat bagi orang yang } \\
\text { menggunakannya (Davis, 1993) }\end{array}$ & $\begin{array}{l}\text { 1) Meningkatkan kinerja } \\
\text { 2) Memudahkan pekerjaan } \\
\text { 3) Merasakan keseluruhan } \\
\text { manfaat teknologi }\end{array}$ \\
\hline 2. & $\begin{array}{l}\text { Perceived } \\
\text { ease of } \\
\text { use (X2) }\end{array}$ & $\begin{array}{l}\text { Kemudahan penggunaan didefinisikan } \\
\text { sebagai sejauh mana orang percaya } \\
\text { bahwa menggunakan suatu teknologi } \\
\text { akan bebas dari usaha (Davis, 1985: } 25 \text { ) }\end{array}$ & $\begin{array}{l}\text { 1) Kemudahan sistem untuk } \\
\text { dipelajari (easy of learn), } \\
\text { 2) Kemudahan system untuk } \\
\text { dikontrol (controllable) } \\
\text { 3) Interaksi dengan system } \\
\text { yang jelas dan mudah } \\
\text { dimengerti (clear and } \\
\text { understandable) } \\
\text { 4) Fleksibilitas interaksi } \\
\text { (flexibility), } \\
\text { 5) Mudah untuk terampil } \\
\text { menggunakan system (easy } \\
\text { to become skillful) } \\
\text { 6) Mudah untuk digunakan } \\
\text { (easy to use) }\end{array}$ \\
\hline 3. & $\begin{array}{l}\text { Attitude } \\
\text { toward } \\
\text { using } \\
\text { (X3) }\end{array}$ & $\begin{array}{l}\text { Sikap terhadap penggunaan sistem yang } \\
\text { berbetuk penerimaan atau penolakan } \\
\text { sebagai dampak bila seseorang } \\
\text { menggunakan teknologi dalam } \\
\text { pekerjaannya (Davis, 1993) }\end{array}$ & $\begin{array}{l}\text { 1) Unsur kognitif/cara } \\
\text { pandang (cognitive) } \\
\text { 2) Afektif (affective) } \\
\text { 3) Behavioral components }\end{array}$ \\
\hline 4. & $\begin{array}{l}\text { Actual } \\
\text { Use (Y) }\end{array}$ & $\begin{array}{l}\text { Sebuah perilaku nyata dalam mengadopsi } \\
\text { suatu sistem. Actual system usage } \\
\text { diartikan sebagai bentuk respon } \\
\text { psikomotor eksternal yang diukur oleh } \\
\text { seseorang dengan penggunaan nyata } \\
\text { (Davis, 1989). }\end{array}$ & $\begin{array}{l}\text { 1) Penggunaan teknologi } \\
\text { yaitu penggunaan } \\
\text { sesungguhnya. } \\
\text { 2) Frekuensi sesungguhnya. } \\
\text { 3) Kepuasan pengguna. }\end{array}$ \\
\hline
\end{tabular}

\section{Jenis dan Sumber Data}

Dalam penelitian ini menggunakan data primer. Data primer merupakan data yang bersumber dari tangan pertama, data yang diambil menggunakan cara kuesioner(Hakim et al., 2020).

\section{Metode Pengumpulan Data}

Untuk mengumpulkan data tersebut, peneliti memilih kuesioner sebagai metode untuk mengumpulkan data. Kuesioner yang digunakan untuk menilai persepsi responden dalam bentuk pertanyaan tertutup. Daftar pertanyaan tertutup tersebut berisi pertanyaan-pertanyaan yang jawabannya telah disediakan dengan menggunakan penilaian 5 untuk jawaban Sangat Setuju (SS), 4 untuk jawaban Setuju (S), 3 untuk jawaban Netral (N),2 untuk jawaban Tidak Setuju (TS),1 untuk jawaban Sangat Tidak Setuju (STS). 


\section{E. Uji Instrumen Penelitian \\ 1. Uji Validitas}

Jika masing-masing pertanyaan merupakan indikator pengukur maka memiliki KMO diatas 0,5 dan signifikansi dibawah 0,05 serta memiliki nilai kriteria loading faktor pengujian sebagai berikut (Ghozali, 2011):

- Loading faktor > rule of tumb $(0,4)$ berarti valid

- Loading faktor < rule of tumb $(0,4)$ berarti tidak valid

\section{Uji Reliabilitas}

Pengukuran reliabilitas dapat dilakukan dengan koefisien Alpha Cronbach menggunakan SPSS For Windows (Ghozali, 2011) dengan kriteria:

- Bila nilai alpha $>0,7$ maka instrumen reliabel

- Bila nilai alpha $<0,7$ maka instrumen tidak reliable

\section{F. Uji Normalitas.}

Pengambilan kesimpulan untuk menentukan apakah suatu data mengikuti distribusi normal atau tidak adalah dengan menilai nilai signifikannya. Jika signifikan >0,05 maka variabel berdistribusi normal dan sebaliknya jika signifikan <0,05 maka variabel tidak berdistribusi normal (Ghozali, 2011).

\section{G. Uji Model}

Uji model data dalam penelitian ini menggunakan Koefisien determinasi (R2). Koefisien determinasi (R2) digunakan untuk mengetahui besarnya persentase goodness of fit dari variabel independent terhadap variabel dependent (Ghozali, 2011).

\section{H. Uji Hipotesis}

Uji hipotesis menggunakan uji t yaitu untuk mengidentifikasi pengaruh variabel independent terhadap variabel dependent dengan menggunakan SPSS dengan taraf signifikan (a) $<0,05$ (Astriawati, 2016). Hipotesis diterima jika taraf signifikan $<0,05$ dan hipotesis ditolak jika taraf signifikan $>0,05$.

\section{PEMBAHASAN}

\section{Identitas Responden berdasarkan Jenis Kelamin}

Tabel 3. Jenis Kelamin Responden

\begin{tabular}{rrrrr}
\hline & Frequency & Percent & Valid Percent & Cumulative Percent \\
\hline Pria & 92 & 92.0 & 92.0 & 92.0 \\
Valid Wanita & 8 & 8.0 & 8.0 & 100.0 \\
Total & 100 & 100.0 & 100.0 & \\
\hline
\end{tabular}

Sumber : Data primer yang diolah, 2020

Peserta Penilaian Training Record Book di bawah PUKP 05 sebagai responden mayoritas Pria (92.0\%) dan minoritas Wanita dengan 8,0\%.

\section{Identitas Responden Berdasarkan Umur}

Tabel 4. Umur Responden 


\begin{tabular}{rrrrr}
\hline & Frequency & Percent & Valid Percent & Cumulative Percent \\
\hline Valid 12-25 & 100 & 100,0 & 100,0 & 100,0 \\
\hline
\end{tabular}

Sumber : Data primer yang diolah, 2020

Responden seluruhnya berusia 12 - 25 tahun sebesar $100 \%$.

\section{Identitas Responden Berdasarkan Asal Diklat}

Tabel 5. Asal Diklat Responden

\begin{tabular}{llrrr}
\hline & Frequency & Percent & Valid Percent & Cumulative Percent \\
\hline \multirow{4}{*}{ Valid } & 17 & 17.0 & 17.0 & 17.0 \\
SMK Pelayaran & 83 & 83.0 & 83.0 & 100.0 \\
Total & 100 & 100.0 & 100.0 & \\
\hline
\end{tabular}

Sumber : Data primer yang diolah, 2020

Responden sebagian besar berasal dari tingkat Akademi Pelayaran yaitu $83.0 \%$, sisanya $17,0 \%$ dari siswa SMK Pelayaran.

\section{Identitas Responden Berdasarkan Kota Asal}

Tabel 6. Kota Asal Responden

\begin{tabular}{llrrr}
\hline & Frequency & Percent & Valid Percent & Cumulative Percent \\
\hline \multirow{2}{*}{ Valid Luar Semarang } & 36 & 36.0 & 36.0 & 36.0 \\
Total & 64 & 64.0 & 64.0 & 100.0 \\
\hline
\end{tabular}

Sumber : Data primer yang diolah, 2020

Responden sebanyak $36.0 \%$ berasal dari Semarang dan sebanyak $64.0 \%$ berasal dari luar Semarang.

\section{A. Deskripsi Variabel}

Data dalam penelitian ini merupakan skala pengukuran yang dikuantifikasikan dengan pemberian skor dalam skala likert, yaitu angka 1 sampai dengan 5, yang mewakili pernyataan "sangat tidak setuju", "tidak setuju", "netral", "setuju", dan "sangat setuju" dimana angka-angka tersebut menunjukkan suatu posisi berdasarkan atas tanggapan para responden terhadap masing-masing item atau indikator pertanyaan sebagai berikut :

\section{Variabel Perceived ease of use ( Kemudahan Penggunaan ) (X1)}

Hasil penelitian Perceived ease of use (Kemudahan Penggunaan) terhadap Actual usage baik, hal ini dilihat dari indikator pertanyaan menunjukkan rata-rata setuju.

\section{Variabel Perceived usefulness (Kemanfaatan) (X2)}

Hasil penelitian Perceived usefulness (Kemanfaatan) terhadap Actual usage tinggi, dilihat dari indikator pertanyaan menunjukkan rata-rata setuju.

\section{Variabel Attitude toward using (Sikap) (X3)}

Hasil penelitian Attitude toward using baik, hal ini dilihat dari indikator pertanyaan menunjukkan rata-rata setuju.

\section{Variabel Actual usage (Y)}

Hasil penelitian Actual usage baik, hal ini dilihat dari indikator pertanyaan menunjukkan rata-rata setuju. 


\section{B. Uji Instrumen Penelitian \\ 1. Uji Validitas Indikator \\ a. Indikator Variabel Perceived ease of use}

Tabel 7. Hasil Pengujian Validitas Indikator Variabel Perceived ease of use.

\begin{tabular}{lll}
\hline & \multicolumn{2}{c}{ Component } \\
\cline { 2 - 3 } $\mathrm{X} 1.1$ & \multicolumn{2}{c}{1} \\
\cline { 2 - 3 } $\mathrm{X} 1.2$ & .736 \\
$\mathrm{X} 1.3$ & .733 \\
$\mathrm{X} 1.4$ & .527 \\
$\mathrm{X} 1.5$ & .806 \\
\hline
\end{tabular}

Sumber : Data primer yang diolah, 2020

Dari tabel diatas terlihat bahwa 5 indikator variabel Perceived ease of use memenuhi ketentuan kecukupan sampel >0,5 yaitu 0,746 sehingga dapat dikatakan secara signifikan membentuk pengukur variabel Perceived ease of use. Dan selanjutnya 5 indikator tersebut dilakukan uji reliabilitas.

\section{b. Indikator Variabel Perceived usefulness}

Tabel 8. Hasil Pengujian Validitas Indikator Variabel Perceived usefulness

\begin{tabular}{lr}
\hline & \multicolumn{2}{c}{ Component } \\
\cline { 2 - 2 } X2.1 & .734 \\
$\mathrm{X} 2.2$ & .811 \\
$\mathrm{X} 2.3$ & .672 \\
$\mathrm{X} 2.4$ & .712 \\
\hline
\end{tabular}

Sumber : Data primer yang diolah, 2020

Dari tabel diatas terlihat bahwa 4 indikator variabel Perceived usefulness memenuhi ketentuan kecukupan sampel >0,5 yaitu 0,710 sehingga dapat dikatakan secara signifikan membentuk pengukur variabel Perceived usefulness dan selanjutnya 4 indikator dilakukan uji reliabilitas.

\section{c. Indikator Variabel Attitude toward using}

Tabel 9. Hasil Pengujian Validitas Indikator Variabel Attitude toward using.

\begin{tabular}{lrr}
\hline & \multicolumn{2}{c}{ Component } \\
\cline { 2 - 3 } X3.1 & \multicolumn{2}{c}{1} \\
\cline { 2 - 3 } X3.2 & .646 \\
X3.3 & .744 \\
\hline
\end{tabular}

Sumber : Data primer yang diolah, 2020

Dari tabel diatas terlihat bahwa 3 indikator variabel Attitude toward using memenuhi ketentuan kecukupan sampel > 0,5 yaitu 0,597 sehingga dapat dikatakan secara signifikan membentuk pengukur variabel Attitude toward using. Dari hasil uji validitas semua indikator valid karena 3 indikator tersebut 
mempunyai loading factor > 0,4. Dan selanjutnya 3 indikator dilakukan uji reliabilitas.

\section{d. Indikator Variabel Actual usage}

Tabel 10. Hasil Pengujian Validitas Indikator Variabel Actual usage

\begin{tabular}{lr} 
& \multicolumn{2}{c}{ Component } \\
\cline { 2 - 3 } Y1 & .798 \\
Y2 & .578 \\
Y3 & .728 \\
\hline
\end{tabular}

Sumber : Data primer yang diolah, 2020

Dari tabel diatas terlihat bahwa 3 indikator variabel Actual usage memenuhi ketentuan kecukupan sampel $>0,5$ yaitu 0,560 sehingga dapat dikatakan secara signifikan membentuk pengukur variabel Actual usage. Dari hasil uji validitas semua indikator valid karena 3 indikator tersebut mempunyai loading factor > 0,4. Dan selanjutnya 3 indikator dilakukan uji reliabilitas.

\section{Uji Reliabilitas Indikator}

Pengujian reliabilitas dilakukan dengan menggunakan perhitungan koefisien Cronbach Alpha. Pengujian ini dilakukan dengan cara one short atau pengukuran sekali saja, dengan bantuan perangkat lunak SPSS versi 16.0. Jika pengujian reliabilitas menghasilkan nilai koefisien Cronbach Alpha $(\alpha)>0,70$ (Ghozali, 2011), maka indikator valid yang diuji dapat membentuk variabel yang dikatakan reliabel atau indikator pengukur variabel terpercaya atau dapat dipercaya. Sedangkan jika nilai koefisien Cronbach Alpha $(\alpha)<0,70$ maka indikator pertanyaan yang digunakan untuk mengukur suatu variabel dikatakan tidak reliabel atau tidak terpercaya. Sedang syarat variabel yang baik adalah valid dan reliabel.

Tabel 11. Pengujian Reliabilitas Variabel-variabel Penelitian

\begin{tabular}{clccc}
\hline No. & \multicolumn{1}{c}{ Variabel } & $\begin{array}{c}\text { Alpha } \\
\text { Cronbach }\end{array}$ & $\begin{array}{c}\text { Angka Standar } \\
\text { Reliabel }\end{array}$ & Kriteria \\
\hline 1 & Perceived ease of use $\left(\mathrm{X}_{1}\right)$ & 0,772 & 0,7 & Reliabel \\
2 & Perceived usefulness $\left(\mathrm{X}_{2}\right)$ & 0,714 & 0,7 & Reliabel \\
3 & Attitude toward using $(\mathrm{X} 3)$ & 0,792 & 0,7 & Reliabel \\
3 & Actual usage (Y) & 0,776 & 0,7 & Reliabel \\
\hline
\end{tabular}

Sumber : Data primer yang diolah, 2020

Pada uji reliabilitas tabel 4.13 di atas variabel Perceived ease of use (X1), Perceived usefulness (X2), Attitude toward using (X3) dan Actual usage (Y) dikatakan reliabel karena Alpha Cronbach > 0,7 sehingga layak untuk diujikan ke pengujian selanjutnya.

\section{Analisis Regresi}

\section{Uji Asumsi Klasik}

\section{a. Uji Normalitas}

Normalitas data dapat di lihat dari grafik histogram dan grafik normal P-P plot dengan bantuan program SPSS. Apabila pada grafik histogram memberikan pola distribusi tidak melenceng maka data tersebut dinyatakan berdistribusi 
normal, dan apabila pada grafik normal P-P plot titik titik mendekati garis diagonal, dapat disimpulkan bahwa data berdistribusi normal.

Terlihat grafik P-P plot titik-titik yang terbentuk mendekati garis diagonal, yang berarti data berdistribusi normal.

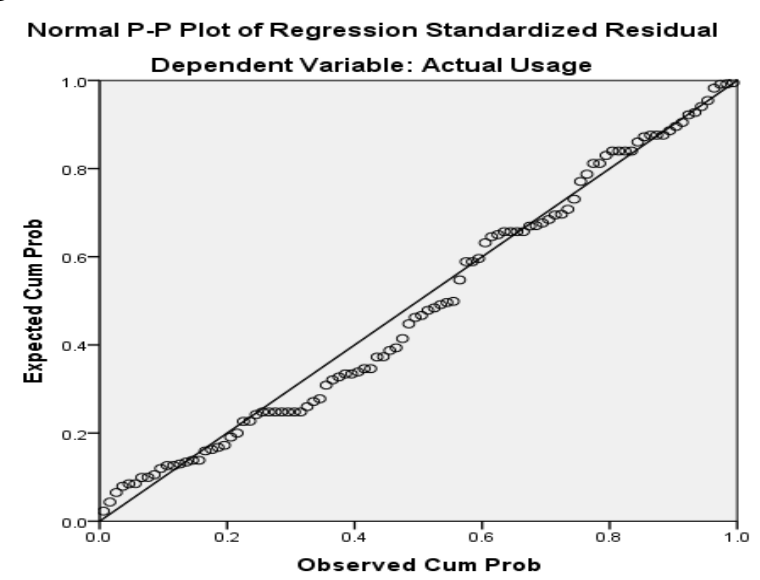

\section{b. Uji Moltikolinearitas}

Model regresi yang baik seharusnya tidak terjadi korelasi antara variabel bebas. Model regresi yang bebas dari moltikolinearitas dilihat jika memiliki nilai VIF $<10$ dan nilai tolerance $>0.1$.

Dari hasil data bahwa nilai VIF masing masing variabel di bawah nilai 10 yaitu Percieved ease of use (kemudaahan) sebesar $1.979<10$, Perceived usefulness sebesar $1.131<10$ dan Attitude toward using sebesar $2.044<10$. Serta nilai tolerance Percieved ease of use (kemudaahan) sebesar $0.505>0.1$, Perceived usefulness sebesar $0.884>0.1$ dan Attitude toward using sebesar 0.489 $>0.1$, sehingga dapat disimpulkan tidak ada multikolinearitas.

\section{Analisis Regresi Berganda}

Pengujian hipotesis yang diajukan dalam penelitian ini menggunakan análisis regresi berganda yang diuji secara parsial. Hasil análisis regresi dengan bantuan program SPSS.

\section{Uji Parsial}

Uji Parsial digunakan untuk menguji kemaknaan koefisien parsial. Apabila signifikansi $<0.05$ maka hipótesis H1, H2, H3, H4 dan H5 di terima, hasil análisis dengan bantuan program SPSS.

\section{a. Pengaruh Perceived ease of use (Kemudahan) (X1) Terhadap Attitude toward using (Sikap) (X3).}

Tabel 12. Hasil Uji Hipotesis Pengaruh Perceived ease of use (Kemudahan) (X1)

Terhadap Attitude toward using (Sikap) (X3).

\begin{tabular}{|c|c|c|c|c|}
\hline \multirow[t]{3}{*}{ Model } & \multicolumn{2}{|c|}{ Unstandardized Standardized } & \multirow[t]{2}{*}{$\mathrm{t}$} & \multirow[t]{2}{*}{ Sig. } \\
\hline & Coefficients & Coefficients & & \\
\hline & $\mathrm{B}$ & Std. Error & Beta & \\
\hline (Constant) & 5.277 & .800 & & 6.595 \\
\hline
\end{tabular}


Sumber : \begin{tabular}{lcccc} 
Kemudahan & .364 & .037 & $.701 \quad 9.736$ \\
\cline { 2 - 4 }
\end{tabular}

Perceived ease of use (Kemudahan) (X1) menghasilkan t hitung 9.736 dan tingkat signifikan $0,000<0,05$ serta nilai beta 0.701 (positif) sehingga terdapat pengaruh positif signifikan Perceived ease of use (Kemudahan) X1 terhadap Attitude toward using (Sikap) X3. Dengan demikian hipotesis pertama (H1) : "Perceived ease of use berpengaruh positif dan signifikan terhadap Attitude toward using Aplikasi Smile 05" diterima.

b. Pengaruh Perceived Usefullness (Kemanfaatan) (X2) Terhadap Attitude toward using (Sikap) (X3).

Tabel 13. Hasil Uji Hipotesis Pengaruh Perceived Usefullness (Kemanfaatan)

(X2) Terhadap Attitude toward using (Sikap) (X3).

\begin{tabular}{crrrr}
\hline Model & $\begin{array}{l}\text { Unstandardized } \\
\text { Coefficients }\end{array}$ & $\begin{array}{c}\text { Standardized } \\
\text { Coefficients }\end{array}$ & t & Sig. \\
\cline { 2 - 6 } & \multicolumn{1}{c}{ B } & Std. Error & Beta & \\
\hline (Constant) & 11.875 & .347 & & 34.180 \\
Manfaat & .064 & .018 & .333 & 3.494 \\
\hline
\end{tabular}

Sumber : Data primer yang diolah, 2020

Perceived usefulness (Kemanfaatan) (X2) menghasilkan t hitung 3.494 dan tingkat signifikan $0,001<0,05$ serta nilai beta 0.333 (positif) sehingga terdapat pengaruh positif signifikan Perceived usefulness (Kemanfaatan) X2 terhadap Attitude toward using (Sikap) X3. Dengan demikian hipotesis kedua H2: "Perceived Usefullness berpengaruh positif dan signifikan Attitude toward using Aplikasi Smile 05" diterima.

c. Pengaruh Perceived ease of use (Kemudahan) (X1) Terhadap Actual usage (Y).

Tabel 14. Hasil Uji Hipotesis Pengaruh Perceived ease of use (Kemudahan) (X1)

Terhadap Actual usage (Y).

\begin{tabular}{lrrrr}
\hline Model & $\begin{array}{l}\text { Unstandardized } \\
\text { Coefficients }\end{array}$ & $\begin{array}{l}\text { Standardized } \\
\text { Coefficients }\end{array}$ & $\mathrm{t}$ & Sig. \\
\cline { 2 - 6 } & \multicolumn{1}{c}{$\mathrm{B}$} & \multicolumn{2}{c}{ Std. Error } & Beta \\
\hline (Constant) & 8.114 & .871 & & 9.320 \\
Kemudahan & .233 & .041 & .502 & 5.738
\end{tabular}

Sumber : Data primer yang diolah, 2020

Perceived ease of use (Kemudahan) (X1) menghasilkan t hitung 5.738 dan tingkat signifikan $0,000<0,05$ serta nilai beta 0.041 (positif) sehingga terdapat pengaruh positif signifikan Perceived ease of use (Kemudahan) X1 terhadap Actual usage (Y). Dengan demikian hipotesis ketiga H3 : "Perceived ease of use berpengaruh positif dan signifikan Terhadap Actual Use Aplikasi Smile 05" diterima. 


\section{d. Pengaruh Perceived usefulness (Kemanfaatan) (X2) Terhadap Actual usage (Y).}

Tabel 15. Hasil Uji Hipotesis Pengaruh Perceived usefulness (Kemanfaatan) (X2)

Terhadap Actual usage (Y).

\begin{tabular}{crrrr}
\hline Model & $\begin{array}{l}\text { Unstandardized } \\
\text { Coefficients }\end{array}$ & $\begin{array}{l}\text { Standardized } \\
\text { Coefficients }\end{array}$ & t & Sig. \\
\cline { 2 - 6 } & \multicolumn{1}{c}{$\mathrm{B}$} & Std. Error & Beta & \\
\hline (Constant) & 12.245 & .318 & & 38.503 \\
Manfaat & .047 & .017 & .271 & 2.783 \\
\hline
\end{tabular}

Sumber : Data primer yang diolah, 2020

Perceived usefulness (Kemanfaatan) (X2) menghasilkan t hitung 2.783 dan tingkat signifikan $0,006<0,05$ serta nilai beta 0.271 (positif) sehingga terdapat pengaruh positif signifikan Perceived usefulness (Kemanfaatan) X2 terhadap Actual usage (Y). Dengan demikian hipotesis keempat $\mathrm{H} 4$ : "Perceived Usefullness berpengaruh positif dan signifikan terhadap Actual Use Aplikasi Smile 05" diterima.

e. Pengaruh Attitude toward using (Sikap) (X3) Terhadap Actual usage (Y).

Tabel 16. Hasil Uji Hipotesis Pengaruh Attitude toward using (sikap) (X3)

Terhadap Actual usage (Y).

\begin{tabular}{crrrr}
\hline Model & $\begin{array}{l}\text { Unstandardized } \\
\text { Coefficients }\end{array}$ & $\begin{array}{c}\text { Standardized } \\
\text { Coefficients }\end{array}$ & t & Sig. \\
\cline { 2 - 5 } & \multicolumn{1}{c}{$\mathrm{B}$} & Std. Error & Beta & \\
\hline (Constant) & 7.207 & 1.024 & & 7.041 \\
Sikap & .451 & .078 & .503 & 5.762 \\
\hline
\end{tabular}

Sumber : Data primer yang diolah, 2020

Attitude toward using (Sikap) (X3) menghasilkan t hitung 5.762 dan tingkat signifikan $0,000<0,05$ serta nilai beta 0.503 (positif) sehingga terdapat pengaruh positif signifikan Attitude toward using (Sikap) (X3) terhadap Actual usage (Y). Dengan demikian hipotesis kelima H5 : "Perceived Attitude toward using berpengaruh positif dan signifikan terhadap Actual Use Aplikasi Smile 05" diterima.

\section{Koefisian Determinasi}

Tabel 17. Hasil Koefisian Determinasi

\begin{tabular}{ccccr}
\hline Model & $\mathrm{R}$ & R Square & $\begin{array}{c}\text { Adjusted R } \\
\text { Square }\end{array}$ & Std. Error of the Estimate \\
\hline 1 & $.553 \mathrm{a}$ & .305 & .284 & .922 \\
\hline
\end{tabular}

Sumber : Data primer yang diolah, 2020

Berdasarkan table diatas besarnya konstribusi secara bersama sama Perceived ease of use (kemudahan), Perceived usefulness (kemanfaatan), Attitude toward using (sikap) terhadap Actual usage pengguna pendaftaran 
online (Smile 05) TRB, adalah sebesar 0.305 atau 30.5\% sedangkan sisanya $69.5 \%$ dipengaruhi oleh factor lain yang tidak di kaji dalam penelitian ini.

\section{Pembahasan}

Penelitian yang dilakukan untuk mengetahui pengaruh Perceived ease of use (kemudahan), Perceived usefulness (kemanfaatan), Attitude toward using (sikap) terhadap Actual usage pengguna pendaftaran online (Smile 05) TRB di bawah wilayah kerja pukp 05 adalah sebagai berikut :

\section{Pengaruh Perceived ease of use ( Kemudahan) X1 Terhadap Attitude} toward using (Sikap) X3

Berdasarkan hasil analisis regresi uji parsial diperoleh nilai sig. $0.000<0.05$ dapat dilihat bahwa Perceived ease of use atau kemudahan penggunaan mempunyai pengaruh yang signifikan dan mempunyai kontribusi terhadap Attitude toward using atau sikap pengguna. Artinya bahwa semakin mudah penggunaan suatu aplikasi, mudah di mengerti, jelas terhadap informasi yang di sampaikan serta adanya keunggulan teknologi pada suatu aplikasi maka akan dapat merubah sikap pengguna untuk tertarik menggunakannya.

2. Pengaruh Perceived usefulness (kemanfaatan) X2 Terhadap Attitude toward using (Sikap) X3

Berdasarkan hasil analisis regresi uji parsial diperoleh nilai sig. $0.001<0.05$ dapat dilihat bahwa Perceived usefulness atau kemanfaatan penggunaan mempunyai pengaruh yang signifikan dan mempunyai kontribusi terhadap Attitude toward using atau sikap pengguna. Semakin bermanfaat suatu aplikasi dalam mempercepat sebuah proses pekerjaan dan memiliki nilai efisiensi maka akan merubah sikap pengguna untuk tertarik menggunakannya.

\section{Pengaruh Perceived ease of use (kemudahan) X1 Terhadap Actual usage} (Y)

Berdasarkan hasil analisis regresi uji parsial diperoleh nilai sig. $0.000<0.05$ dapat dilihat bahwa Perceived ease of use atau kemudahan penggunaan mempunyai pengaruh yang signifikan dan mempunyai kontribusi terhadap Actual usage, hal ini menunjukkan bahwa variasi Actual usage penguna mampu dijelaskan oleh variasi kemudahan dari alat atau aplikasi yang digunakan. Semakin mudah penggunaan suatu aplikasi, mudah di mengerti, jelas terhadap informasi yang di sampaikan serta adanya keunggulan teknologi pada suatu aplikasi maka akan membawa pengguna untuk tertarik menggunakan seterusnya atau frekuensi penggunaan meningkat hal tersebut sebagai akibat dari rasa puas pengguna terhadap aplikasi yang digunakan serta keinginan untuk menyampaikan rasa puasnya terhadap orang lain.

\section{Pengaruh Perceived usefulness (kemanfaatan) X2 Terhadap Actual usage}

\section{(Y)}

Berdasarkan hasil analisis regresi uji parsial diperoleh nilai sig. $0.006<0.05$ dapat dilihat bahwa Perceived usefulness atau kemanfaatan suatu alat mempunyai pengaruh yang signifikan dan mempunyai kontribusi terhadap Actual usage, hal ini menunjukkan bahwa variasi Actual usage penguna mampu dijelaskan oleh variasi kemanfaatan dari alat atau aplikasi yang digunakan. Semakin bermanfaat suatu aplikasi dalam mempercepat sebuah proses pekerjaan dan memiliki nilai 
efisiensi maka akan membawa pengguna untuk tertarik menggunakan seterusnya atau frekuensi penggunaan meningkat hal tersebut sebagai akibat dari rasa puas pengguna terhadap aplikasi yang digunakan serta keinginan untuk menyampaikan rasa puasnya terhadap orang lain.

\section{Pengaruh Attitude toward using (sikap) X2 Terhadap Actual usage (Y)}

Berdasarkan hasil analisis regresi uji parsial diperoleh nilai sig. $0.000<0.05$ dapat dilihat bahwa Attitude toward using atau sikap penggunaan mempunyai pengaruh yang signifikan dan mempunyai kontribusi terhadap Actual usage atau frekuensi penggunaan, hal ini menunjukkan bahwa variasi Actual usage atau frekuensi penggunaan aplikasi oleh penguna mampu dijelaskan oleh variasi sikap dari pengguna aplikasi. Semakin positif sikapnya dalam penggunaan suatu aplikasi dan menganggap sebagai suatu ide yang bagus maka akan membawa pengguna untuk tertarik menggunakan seterusnya atau frekuensi penggunaan meningkat hal tersebut sebagai akibat dari rasa puas pengguna terhadap aplikasi yang digunakan serta keinginan untuk menyampaikan rasa puasnya terhadap orang lain.

\section{PENUTUP}

\section{Kesimpulan}

Dalam penelitian ini didapatkan dukungan yang signifikan dimana memperkuat konsep bahwa Actual Use atau frekeunsi penggunaan aplikasi dipengaruhi oleh faktor-faktor Perceived ease of use, Perceived usefulness, dan Attitude toward using. Dari hasil analisis yang telah dilakukan dapat dikembangkan beberapa pernyataan yang didukung bukti empiric sebagai berikut:

1. Perceived ease of use atau kemudahan penggunaan mempunyai pengaruh yang signifikan dan mempunyai kontribusi terhadap Attitude toward using atau sikap pengguna, hal ini menunjukkan bahwa variasi sikap penguna mampu dijelaskan oleh variasi kemudahan penggunaan. Artinya bahwa semakin mudah penggunaan suatu aplikasi, mudah di mengerti, jelas terhadap informasi yang di sampaikan serta adanya keunggulan teknologi pada suatu aplikasi makaakan dapat merubah sikap pengguna untuk tertarik menggunakannya.

2. Perceived usefulness atau kemanfaatan penggunaan mempunyai pengaruh yang signifikan dan mempunyai kontribusi terhadap Attitude toward using atau sikap pengguna, hal ini menunjukkan bahwa variasi sikap penguna mampu dijelaskan oleh variasi kemanfaatan dari alat atau aplikasi yang digunakan. Semakin bermanfaat suatu aplikasi dalam mempercepat sebuah proses pekerjaan dan memiliki nilai efisiensi maka akan merubah sikap pengguna untuk tertarik menggunakannya.

3. Perceived ease of use atau kemudahan penggunaan mempunyai pengaruh yang signifikan dan mempunyai kontribusi terhadap Actual usage (frekuensi penggunaan), hal ini menunjukkan bahwa variasi Actual usage penguna mampu dijelaskan oleh variasi kemudahan dari alat atau aplikasi yang digunakan. Semakin mudah penggunaan suatu aplikasi, mudah di mengerti, jelas terhadap informasi yang di sampaikan serta adanya keunggulan teknologi 
pada suatu aplikasi maka akan membawa pengguna untuk tertarik menggunakan seterusnya atau frekuensi penggunaan meningkat hal tersebut sebagai akibat dari rasa puas pengguna terhadap aplikasi yang digunakan serta keinginan untuk menyampaikan rasa puasnya terhadap orang lain.

4. Perceived usefulness atau kemanfaatan suatu alat mempunyai pengaruh yang signifikan dan mempunyai kontribusi terhadap Actual usage, hal ini menunjukkan bahwa variasi Actual usage penguna mampu dijelaskan oleh variasi kemanfaatan dari alat atau aplikasi yang digunakan. Semakin bermanfaat suatu aplikasi dalam mempercepat sebuah proses pekerjaan dan memiliki nilai efisiensi maka akan membawa pengguna untuk tertarik menggunakan seterusnya atau frekuensi penggunaan meningkat hal tersebut sebagai akibat dari rasa puas pengguna terhadap aplikasi yang digunakan serta keinginan untuk menyampaikan rasa puasnya terhadap orang lain.

5. Attitude toward using atau sikap penggunaan mempunyai pengaruh yang signifikan dan mempunyai kontribusi terhadap Actual usage atau frekuensi penggunaan, hal ini menunjukkan bahwa variasi Actual usage atau frekuensi penggunaan aplikasi oleh penguna mampu dijelaskan oleh variasi sikap dari pengguna aplikasi. Semakin positif sikapnya dalam penggunaan suatu aplikasi dan menganggap sebagai suatu ide yang bagus maka akan membawa pengguna untuk tertarik menggunakan seterusnya atau frekuensi penggunaan meningkat hal tersebut sebagai akibat dari rasa puas pengguna terhadap aplikasi yang digunakan serta keinginan untuk menyampaikan rasa puasnya terhadap orang lain.

\section{DAFTAR PUSTAKA}

Ardianto, Elvinaro. 2010. Metode Penelitian Untuk Public Relatios Kuantitatif Dan Kualitatif. Bandung: Simbiosa Rekatama Media.

Arikunto, Suharsimi. 2013. Prosedur Penelitian Suatu Pendekatan Praktik. Rineka Cipta, Jakarta.

Astriawati, N. (2016). Penerapan Analisis Regresi Linier Berganda Untuk Menentukan Pengaruh Pelayanan Pendidikan Terhadap Efektifitas Belajar Taruna Di Akademi Maritim Yogyakarta. Majalah Ilmiah Bahari Jogja, XIV(regresi liner), 22-37. Retrieved from http://jurnal.amy.ac.id/index.php/MIBJ/article/view/90/89

Davis, F. D. (1989). Perceived usefulness, perceived ease of use, and user acceptance of information technology. MIS Quarterly: Management Information Systems. https://doi.org/10.2307/249008

Devi, N.L.N.S., Suartana, I.W., 2014, Analisis Technology Acceptance Model (TAM) Terhadap Penggunaan Sistem Informasi di Nusa Dua Beach Hotel \& Spa, E-Jurnal Akuntansi Universitas Udayana Vol. 6.1. pp. 167-184.Feist, J., \& Feist, G. J. (2011). Teori kepribadian.(Handriatno, Trans.) Jakarta: Salemba Humanika. 
Ghozali, I. (2011). Aplikasi Analisis Multivariate Dengan Program IBM SPSS 19 (edisi kelima). Aplikasi Analisis Multivariate Dengan Program SPSS.

Hakim, A. R., Wibowo, W., Astriawati, N., Prodi, A., Kapal, P., Tinggi, S., ... Maritim, T. (2020). SISTEM PENDINGIN MESIN DIESEL PADA WHELL LOADER KOMATSU WA120-3CS. Teknovasi, Jurnal, 07, 7685.

Hamzah, Ardi. 2009. Evaluasi Kesesuaian Model Keperilakuan dalam Penggunaan Teknologi Informasi di Indonesi. Universitas Trunojoyo: Yogyakarta.

Handayani, R. (2005). Analisis faktor-faktor yang mempengaruhi minat pemanfaatan sistem informasi dan penggunaan sistem informasi (studi empiris pada perusahaan manufaktur di Bursa Efek Jakarta). PROGRAM PASCA SARJANA UNIVERSITAS DIPONEGORO.

Jogiyanto. 2005. Analisis dan Desain Sistem Informasi. Yogyakarta: Penerbit Andi.

Kartika. 2013. Technology Acceptance Model: Menguji Keefektivan Penerimaan Sistem Informasi Terpadu (Sister) di Lingkungan Universitas Jember. (Online).

Sugiyono. 2010. Metode Penelitian Pendidikan Pendekatan Kuantitatif, kualitatif, dan R\&D. Bandung: Alfabeta 